\title{
humanidades
}

Revista humanidades

Diciembre, $2014 \cdot$ Volumen $4 \cdot \operatorname{ISSN} 2215-3934 \cdot$ pp. 1-37

\section{Universidad S.A.: La nueva voluntad global}

DOI: http://dx.doi.org/10.15517/h.v4i1.16325

Recibido: 17-Marzo-2014 / Aceptado: 19-Mayo-2014

\section{Víctor Alvarado Dávila}

Máster, profesor en la Sede Regional de Guanacaste de la Universidad de Costa Rica.

Correo electrónico: vdavila27@yahoo.com

Más sobre la autor:

Todos los derechos reservados. Universidad de Costa Rica. Esta revista se encuentra licenciada con Creative Commons Reconocimiento-NoComercial-SinObraDerivada 3.0 Costa Rica.

Correo electrónico: humanidades.eeg@ucr.ac.cr / Sitio web: http:/ / revistas.ucr.ac.cr/index.php/humanidades 


\section{Universidad S.A.: La nueva voluntad global}

\section{Resumen}

En este ensayo se analizan, críticamente, los problemas más actuales y urgentes por los que atraviesa la Universidad en la era de la globalización. Así, se destacan los cambios en el funcionamiento institucional y académico, que transforman mediante la figura de la acreditación y de la titulación homogénea- la autonomía universitaria, en vista a los intereses empresariales, tendientes a proteger los derechos de propiedad intelectual privada.

\section{University, Inc.: The new global will}

\section{Abstract}

This essay is a critical analysis of the current and pressing problems that beset the university in the age of globalization, highlighting the changes in institutional and academic performance that - thanks to accreditation practices and the homogenization of degrees - transform university autonomy into institutions that favor business interests and protect intellectual property rights.

Palabras clave: Universidad, globalización, corporaciones, acreditación, autonomía.
Keywords: University, Globalization, Corporations, Accreditation, Autonomy. 
A partir de las adaptaciones de índole curricular y tecnológica que vienen gestadas por las políticas europeas de Bolonia, se establecen semejanzas con los cambios sufridos por otras universidades de América Latina, con el fin de comprender que tales "necesidades" de cambio vienen gestadas más allá de las necesidades internas de cada universidad, que sobrepasan, incluso, a las instancias de los gobiernos de turno, de cada uno de los estados nacionales.

Dichas adaptaciones curriculares y tecnológicas, al favorecer o privilegiar a ciertas disciplinas, llevan a la posibilidad de que otras carreras no 'tecnológicas', como las pertenecientes al circuito de las humanidades (letras, artes y ciencias sociales) entren en el rango de disciplinas en extinción.

Cambios como estos, conducen a muchos autores a plantear hipótesis que se pueden rastrear en sus diagnósticos teóricos y que invitan a preguntarse si tales propuestas provienen del interior de cada una de las universidades o vienen de afuera. Pueda que exista, en ese sentido, una gran responsabilidad compartida entre las autoridades universitarias y la figura aparentemente preponderante de los rectores en esta gran transición. No obstante, dicha propuesta de cambio en la Universidad, también, viene de afuera, es decir, de las instancias gubernamentales, lo que no es nuevo e incluso se ve con normalidad. 
Se ve con normalidad, entonces, que políticos con escasa experiencia y conocimiento, respecto al compromiso ancestral y comunitario de las universidades, exijan una transformación al interior de esta, para que calce con los objetivos de gobierno, lo que puede significar que conciben a la Universidad como una cosa, como un objeto, como un medio para alcanzar fines gubernamentales. Asimismo, otras peticiones externas de transformación universitaria, vienen de más allá, o de más arriba. Se plantea, de esa forma, ¿qué es lo que quieren las magnas corporaciones de la Universidad?

Son profundos los estudios que, hablando de "capitalismo académico", ponen al desnudo los apetitos de las nacientes y "prometedoras" Universidades S.A. que inauguran, incentivan o exigen, una nueva actitud empresarial por parte de los investigadores, docentes, administrativos y estudiantes, para que puedan justificar su permanencia (o existencia) en el nuevo 'planeta' universitario.

Entre las peticiones o exigencias comúnmente admitidas -sin importar de dónde vengan- están las que tienen que ver con la evaluación y la acreditación. Respecto a la necesidad de la evaluación, más bien se vende la idea positiva como una forma de autoevaluación a lo interno de cada universidad, pero no es ni absurdo ni atrevida una postura escéptica sobre ese tópico, por lo que sería sano preguntar: ¿esta evaluación o 
autoevaluación a qué debe responder?, ¿responde acaso a los ideales íntimos de cada universidad o se valora respecto a fines foráneos?

Se presenta, además, la figura de la acreditación, que parece obedecer a parámetros globales y globalizantes de educación. Hoy se sabe que las universidades que voluntariamente se inscriban en el sendero de acreditación, son recompensadas, pero ¿qué pasará con las universidades no acreditadas?, o mejor aún, ¿en la nueva era es posible pensar en la supervivencia de universidades no acreditadas?, ¿quién querrá estudiar en estas?, ¿y quiénes permitirían la fantasiosa idea del funcionamiento de universidades no acreditadas? y volviendo atrás ¿quién y cómo se premia a las universidades acreditadas? Finalmente ¿a dónde nos llevará todo esto?, ¿cómo concebirán el mundo los educados en estas universidades acreditadas?

Ante este panorama ¿qué pasa con la manera tradicional de interpretar la autonomía universitaria?, ¿se nos dirá que a una nueva Universidad una nueva noción de autonomía? Quizás ya ni siquiera pasa por la mente de los actuales universitarios, pensar la autonomía en términos de financiamiento, quizás eso ya no es problema, porque la solución ya ha sido dada, aunque sea nauseabunda, pero ¿qué de la autonomía en términos de investigación?, ¿será que poderes privados decidirán por los investigadores, sobre qué pueden o deben investigar?, ¿acaso tenemos aún la esperanza de que la 
“autonomía de financiamiento" no contagie la "autonomía de investigación"?

Si lo anterior puede desalentar al romántico humanista de antaño, ¿qué sucedería si se le dijera que debe ahora revertir sus valores morales de lealtad, antiguamente depositados en los sectores más desposeídos y desprotegidos de la sociedad, para invertirlos en los derechos de propiedad intelectual, como muestra de lealtad a la Corporación Universitaria?, ¿si nos apresuramos fatídicamente a los acontecimientos, nos dicen los optimistas? Ojalá sea así. Ojalá también nos equivoquemos en creer que actualmente muchas universidades contratan profesores sin grados académicos, con el timo de que son genios de 'reconocido prestigio' ([...] ¿reconocidos por quiénes?, ¿por los medios de difusión masiva que premian e institucionalizan a charlatanes como luminarias artísticas, intelectuales o científicas?)

Ojalá todas estas dudas no sean más que delirios, producto de un mal sueño. Quizás también echemos por bajo las malas vibras del vox populi, que secretamente chismorrea que los nuevos universitarios han de retribuir (como parte de los intereses adeudados y pactados) mano de obra gratis a las empresas que les financiaron sus estudios. Pero no nos apresuremos, tratemos de ver las cosas más de cerca, aunque la náusea y el sentimiento de absurdo brote de nuestras mentes y corazones. Quizás sea mejor ver la 
muerte con los ojos abiertos, para que reconozca en nuestro duelo, nuestro dolor y nuestro desprecio.

Entre los cambios que se vienen aplicando desde los países poderosos al interior de las universidades en todo el orbe, se encuentran las llamadas “adaptaciones” de índole curricular y tecnológica.

\section{Adaptaciones} intrauniversitarias

Referente a las “Adaptaciones Tecnológicas”, estas van más allá del aprendizaje y el uso de las nuevas tecnologías, y las tutorías personales, y de todas las posibilidades que permite internet. Se busca instaurar, también, el tan cuestionado "sistema de evaluación continua", el cual, podría no estar mal, si no cae en manos de un pequeño grupo que se arroja la potestad de evaluar, sin obligación de entrar ellos mismos en su sistema de evaluación continua, en otras áreas en las que son novicios. Finalmente, es un asunto que se establece desde los nichos de poder al interior de las estructuras universitarias, y no desde el consenso consultado y discutido a lo interno de la comunidad docente universitaria.

Por otra parte, respecto a las llamadas "adaptaciones curriculares", se hace menester, recordar primero, la Declaración de Bolonia, que firmaron en 1999 los ministros de educación de la Unión Europea, con el fin de regular y estandarizar el Espacio Europeo de Educación Superior (EEES), y que 
luego se extendería como una voluntad de poder educativo por el resto del mundo. Así, desde hace tiempo, la nueva política de la educación pretende globalizar el nombre de los títulos en cada uno de los países de la unión europea. Las titulaciones nacidas en este seno, serían reconocidas en todos los países firmantes, facilitando así el intercambio de los titulados.

Referente a este punto (adaptaciones curriculares), el proceso de Bolonia, apunta a un sistema de homogeneización de los títulos, que, adoptando el modelo anglosajón, comprende los tres niveles conformados por grado, máster y doctorado. Se establece también, obviamente, un sistema internacional de créditos, bajo la figura del ECTS: European Credit Transfer System (Sistema Europeo de Transferencia de Créditos). Todo esto permitirá, dentro de la norma establecida por el "Espacio Europeo de Educación Superior" (EEES), la movilidad "efectiva" de profesores, estudiantes, investigadores y personal docente, a cualquier universidad que se una a la nueva estructura de la educación superior globalizada.

Las implicaciones existenciales que, a simple vista pocos pueden ver, resalta la inestabilidad vivencial de los trabajadores, docentes e investigadores, al estar propensos a ser trasladados a otros ambientes (no solo geográficos y culturales) que pueden alterar negativamente sus relaciones afectivas $-\mathrm{y}$ de otra índole- con sus seres queridos y proyectos o hábitos cotidianos. 
Ahora bien, en el nuevo sistema educativo, las titulaciones solo podrán justificarse respecto a su relevancia para el desarrollo del conocimiento y de acuerdo a las necesidades y exigencias del mercado laboral europeo, así, el Real Decreto Español (Capítulo III, art. 9, punto 3), estableció:

Para el establecimiento de un título oficial de Grado, el informe del Consejo de Coordinación Universitaria deberá contener referencia expresa, al menos, a los siguientes aspectos:

[...] d) Relevancia del título para el desarrollo del conocimiento y para el mercado laboral español y europeo (BOE, 2005).

Todo esto puede significar que las titulaciones de áreas que no sean relevantes, respecto a las necesidades y exigencias del mercado laboral, serán fácilmente descartadas por el nuevo sistema educativo mundial. En este sentido, quizás no sea tan desquiciado pronosticar que las áreas de artes y letras, se vayan minimizando cada vez más, hasta entrar en el rango de "carreras en extinción".

La nueva estructura universitaria es concebida actualmente como un negocio, como una inversión. Ya Skilbeck (2001) aseveró que la universidad ya no es más un lugar tranquilo para enseñar, realizar trabajo académico a un ritmo pausado y contemplar el universo como ocurría en 
siglos pasados. Ahora es un potente negocio, complejo, demandante y competitivo que requiere inversiones continuas y de gran escala.

La pugna tradicional por el poder institucional al interior de las universidades, creció motivada por las reformas educativas, que generaron, por un lado, movimientos de resistencia, y por otro, grupos de apoyo a las autoridades universitarias. Dicho panorama condujo a incrementar el poder de la administración central y, en especial, el poder de las rectorías universitarias. El poder institucional y administrativo de las universidades, se ha ido personificando en la figura de los rectores, que han actuado como los principales promotores de los cambios y ajustes de las reformas planteadas. Al respecto, Acosta Silva en su minucioso estudio titulado "Estado, políticas y universidades en un período de transición" aseguró:

Las reformas incrementaron el poder de la administración central, con el objeto no sólo de promover diversas modificaciones sino fundamentalmente con el de contar con la capacidad de aplicarlas en cada universidad. Los periodos de crisis y conflicto que ocurrieron en cada caso reflejaron movimientos de resistencia y de apoyos que alteraron la vida institucional, pero que finalmente se resolvieron en el fortalecimiento de las capacidades de los poderes centrales universitarios [...] En esta perspectiva, las reformas observadas mostraron el incremento del poder de las rectorías universitarias, que

\section{Traiciones internas $\mathbf{y}$ disciplinas en extinción}


se convirtieron en los actores centrales de las transformaciones observadas. Los antiguos equilibrios y 'empates' políticos entre las distintas fuerzas organizadas de la universidad, fueron rotos por coaliciones y redes de poder que cristalizaron alrededor de la figura de los rectores, dotando a estas figuras de hipercentralidad indiscutible tanto en las iniciativas como en los procesos de instrumentación de los cambios y ajustes (2000, p. 326).

Así las cosas, las reformas educativas recientes premian a las facultades, escuelas, investigadores y docentes que felizmente se sumen a la estandarización global, acrecentando así la brecha de desigualdad entre la comunidad universitaria.

Según Acosta, el más ambicioso de los programas del gobierno federal para el periodo 1995-2000 “significó una profundización de los estímulos a la estandarización cuyos efectos parecen orientarse, sin embargo, a una diferenciación y desigualdad creciente en los cuerpos académicos de las universidades públicas" (2000, p. 325). Dicha apreciación nos lleva a comprender lo que Slee y Ball, denominan por "capitalismo académico", el cual se define como el fenómeno "donde la investigación es simplemente un instrumento económico y donde el investigador es exhortado a convertirse en "emprendedor" en alianzas con la industria para crear agendas de investigación que a su vez demuestren ser económicamente productivas" (Muela, 2005, p. 9). Lo que conduce a una mecánica de extinción de ciertas 
disciplinas. Al respecto, Muela explica cómo en México algunas Universidades S.A. de C.V. asociadas al Estado Empresarial han erradicado algunas disciplinas:

Los más cuestionables y afrentosos contra el dominio público se dan en el estado de Nuevo León, donde han desmantelado las licenciaturas de filosofía, sociología e historia. Pero lo que ocurre en Nuevo León, como en todos los países, no es un hecho aislado, es una política de estado. En este caso el estado mexicano a través de la Secretaría del Trabajo y Previsión Social de su poder ejecutivo, ha iniciado una cruzada oficial para desmantelar las carreras de filosofía, sociología y ciencias políticas en las universidades públicas para dar preeminencia únicamente a las carreras que se adapten a sus intereses neo-liberales de su estado empresarial (2005, p. 10).

Lo ya sucedido en otras universidades latinoamericanas puede que ya esté tomando mucho vuelo en nuestro horizonte, sin que conscientemente nos percatemos de ello. Quizá una mañana nos despertemos y veamos una universidad que no reconozcamos y que ya sea imposible de ser recobrada.

En términos generales, estamos de acuerdo en que constantemente las universidades deben de autoevaluar su función docente, sus institutos de investigación y en especial, su acción social, en relación a sus propios ideales y objetivos. Pero el asunto se torna oscuro cuando la "evaluación"

\section{De la evaluación (¿en manos de quién?)}


viene desde afuera, obediente a un sistema de acreditación global. Aunque autores como Ayarza aseguren lo siguiente:

Existe un criterio pragmático y consensuado en cuanto a cuáles son los parámetros y componentes de la calidad, dejando a cada institución la opción para definir sus propios patrones sobre la base de referentes valóricos y a las orientaciones que la determinan en función de su proyecto y su axiología (1997, p. 347).

A pesar de los precedentes, antes habría que asegurar que tal "criterio consensuado", brote del interior de cada comunidad universitaria. Quizás así, se podría aceptar lo siguiente:

Los componentes mencionados son: relevancia, efectividad, disponibilidad de recursos, eficiencia, eficacia y procesos. Esta forma de conceptualizar la calidad permite medirla e incorporar dentro de un solo contexto global diversos aspectos como la pertinencia y la eficiencia interna, que muchos autores consideran en forma separada. Además, genera una opción que es altamente significativa al evitar la competencia absurda entre instituciones, permitiendo por el contrario que cada institución compita consigo misma para estar en constante proceso de mejoramiento (Ayarza, 1997, p. 348). 
Puede que exista un consenso (¿pero entre quiénes?) respecto a los parámetros y componentes de la calidad. Sin embargo, ¿en efecto se deja a cada universidad la libertad de definir sus propios patrones en relación a sus proyectos y valores? Esto suena muy bonito en el papel, pero ¿tienen las universidades tal libertad? Y, por otra parte ¿está la Universidad construyendo sus propios patrones de calidad de manera democrática, o se hace calladamente al interior, dejando tal construcción en manos de las autoridades políticas de la institución, sin tomar en cuenta al resto de la comunidad universitaria?

Rescatable es la crítica de Zubillaga (1996) cuando sentencia:

Antes de emitir juicios de calidad es necesario ponerse de acuerdo sobre el conjunto de atributos que caracterizan a un determinado objeto, en nuestro caso la «universidad». ¿Qué es una Universidad? ¿Qué hace? ¿Cómo lo hace? ¿En qué marco institucional? ¿En qué contexto gnoseológico?, son cuestiones previas referidas a condiciones de esencia y de existencia que deben ser discutidas y resueltas claramente para estar en condiciones de definir aquellos atributos (Trindade, 1997, p. 593). 
Contra el ideal de nueva Universidad, promovido por las magnas corporaciones que gestaron un "Estado - Evaluador" de sus recursos, en términos de "eficacia" y rentabilidad, se hace menester poner en evidencia que "la eficiencia es considerada como un objetivo en sí, sin tomar en cuenta la eficacia social de las universidades en el cumplimiento de su misión pública" (Trindade, 1997, p. 595).

Finalmente, respecto a la susodicha evaluación y calidad académica de la Universidad en América Latina, Helgio Trindade concluye:

Lo que en última instancia, pretende conocer la Comisión Nacional de Evaluación es si una institución universitaria concreta está cumpliendo con su misión pública. Tal perspectiva parece fundamental: cumplir con la misión pública debe ser el criterio básico del proceso evaluativo. Una especialista brasileña en evaluación, Ana María Saul, prefiere hablar de «evaluación emancipadora», en el sentido de que la universidad está orientada hacia una utilidad social, sin la cual su actividad - fin no es pertinente. Estos dos conceptos se correlacionan: solamente una evaluación emancipadora será capaz de evaluar adecuadamente si la universidad está cumpliendo con su misión pública en la formación de sus profesionales, en la realización de sus investigaciones y en la generación y transmisión del conocimiento. Independientemente del desempeño individual del 
profesor o del departamento, la institución debe de ser vista en su globalidad para evaluar también si la universidad está cumpliendo con su función de servicio público abierto a la sociedad (1997, p. 604).

Entre las especificidades de los mecanismos de la globalización educativa, las universidades más poderosas se arrojan la potestad de establecer los “objetos" y métodos de la investigación académica-científica, premiando a las universidades que voluntariamente acepten los parámetros de la "autoridad académica-científica" representada por ellos.

Las universidades acreditadas son aquellas que asumen, sin cuestionamiento substancial, la autoridad de las universidades más poderosas, que no son necesariamente ni las más antiguas ni las mejores.

Curioso es que se acepte de buenas a primeras los 'Rankings' mundiales de las supuestas mejores universidades.

Entramos aquí, si se quiere, a plantear de nuevo y hasta el cansancio, las antiquísimas interrogantes infantiles: 
-¿Las universidades públicas no acreditadas aparecen en el ranking mundial?

- ¿Todas las universidades aparecidas en el ranking, envían sus representantes como evaluadores para elegir los criterios y los lugares que ocupan las instituciones en los rankings?

-¿Si en los rankings mundiales participan las universidades privadas, no es preciso decir que, criterios privados evalúan a universidades públicas?

-¿No será acaso menos patético que existieran separadamente rankings de universidades privadas y por otra parte, rankings de universidades públicas?

Lo que sucede es que la mezcla de universidades privadas con universidades públicas ${ }^{1}$ da la impresión, al lector ingenuo, de que existe un ente justo, imparcial y carente de intereses subterráneos, a la hora de establecer y nombrar los lugares que ocupan las universidades en el cuestionable ranking internacional.

Depositar la confianza y creer en estos rankings, es como exigirle a las mentes despiertas y críticas que crean en los Premios Nobel. De esto conoce quien haya integrado alguna vez un jurado: ¿Quién lo eligió?, ¿quién elige a quien elige?, ¿y desde qué valores, intereses y parámetros eligen?, ¿y nos exigen a todos que aceptemos los valores y parámetros de una minoría? ¡Al 
carajo con esas necedades!, ¡todo se reduce a relaciones de poder! El poder seduce. O exige mal humorado. Y, si no se le baja la cabeza a sus caprichos, impone sus juicios y valores por la fuerza.

En términos más particulares, la voluntad de acreditación exige implícitamente la obediencia del sector docente a sus políticas. Así, quien no publica en las revistas acreditadas no acumulará puntaje. Y lo curioso es que, quien no haya publicado antes en una revista acreditada no podrá publicar en una revista acreditada. ¿Absurdo no? Es como pedirle al huevo que haya sido antes un gallo. Se promueve con esta lógica, una moral sumisa y servil por parte de los intelectuales y científicos que deseen publicar por vez primera en una revista acreditada, luego de obedecer obviamente, las reglas formales que imponen dichas revistas.

Cumpliendo además con una serie de requisitos burocráticos que no habrían cumplido ni científicos como Einstein, ni intelectuales como Nietzsche, para dar una idea de cómo esto limitará el avance del desarrollo de la investigación universitaria nacional e internacional. Por ejemplo, para que un científico o intelectual pueda publicar en una de las pocas revistas 'acreditadas' por esta comisión extranjera, deberá haber publicado previamente en otra revista "acreditada" o en la misma revista o haber sido mencionado en algún artículo publicado en estas revistas 'acreditadas'. Por lo tanto: $\mathrm{O}$ el profesor universitario se 
hace amigo de la argolla de la sucursal de comisión de "acreditación". ..., o no podrá publicar en estas revistas. ¿Por qué sería importante publicar en estas revistas "acreditadas"?: Porque parte del plan de coacción de la investigación es que: el que no publica en estas revistas parametradas no acumulará puntaje (Zavala, 2003, p. 2).

Entre las reglas formales de publicación están los típicos resúmenes en inglés (la lengua oficial del poder en turno... luego será el mandarín) y el sistema de citación predominante, acaparado por el momento por APA. Gracioso: La "American Psychological Association" es la elegida para citar las fuentes y no alguna "autoridad bibliotecológica".

¿Será acaso que estamos entrando en la era de la obediencia a ciegas?

En algunas universidades mexicanas, la preocupación por la autonomía universitaria dejó de ser un problema desde hace tiempo; no porque su autonomía no esté en peligro, sino porque en los nuevos tiempos tal "Autonomía"
universitaria
"comprometida" autonomía es utópica de ser recobrada (esto bajo el supuesto de que alguna vez se haya vivido en realidad). La preocupación de las nuevas instituciones se enfoca en cuestiones técnicas, tales como la evaluación y la planeación. 
La planeación y la evaluación, en ese orden, se convirtieron en los ejes discursivos y programáticos de los esfuerzos gubernamentales. Asuntos como el de la autonomía universitaria pasaron a segundo término. Ya no fue relevante para la acción estatal que las universidades se autogobernaran, o que éstas pudieran definir su ideología o misiones institucionales en un sentido distinto a las preferencias e intereses gubernamentales, o que pudieran establecer normas particulares para la contratación de su planta laboral, fijaran sus políticas de admisión estudiantil, o de investigación (Acosta, 2000, p. 326).

Son múltiples los problemas por los que transita la comunidad universitaria. En Argentina, por ejemplo, la discusión se centró en un ámbito que llamo 'discursivo', entre la concepción de una “educación pública estatal” y la cada vez más fuerte "educación pública privada". Todo esto aunado a otros tópicos, tales como la autonomía -en la que creen todavía algunos pocos. Así, estamos bastante de acuerdo con Hiller cuando expresa:

En el caso de la universidad, los universitarios defendemos su carácter estatal, pero defendemos también la autonomía de la actividad científica creativa. De ninguna manera quisiéramos el control estatal sobre nuestra producción intelectual. Una cosa es que el Estado sostenga, a través del presupuesto nacional, la actividad científico- 
técnica de las universidades, integradas a un plan de desarrollo científico general, y otra muy distinta, e inaceptable, sería el control al desarrollo del libre pensamiento de los universitarios, a la autonomía académica (2003, p. 90).

En efecto, es claro que, de ninguna manera quisiéramos el control estatal sobre nuestra producción intelectual. Pero ¿es esto posible en nuestro país? En verdad, ¿las universidades operan sin el control estatal en lo referente a su producción intelectual?, ¿no es a su vez regulado el MEP por los intereses o intencionalidades de los gobiernos de turno?

Ahora bien, si esto es un problema compartido, al que se enfrenta la educación primaria, secundaria y universitaria, eso no es nada en comparación a la incidencia de otras voluntades de poder supraestatal, sobre lo que deben de investigar las universidades estatales.

Luego de que las instituciones públicas se convierten en deudoras de las corporaciones multinacionales que ahora las financian, deberán de corresponder a los caprichos de estas. Así por ejemplo, si INTEL financia al ITCR, será lógico que este obedezca al primero, respecto al tipo de profesional que debe capacitar, para complacer las demandas de la transnacional que la apadrina. Así las cosas, si algunos docentes universitarios -y voy más allá- no queremos el control estatal sobre nuestra 
producción intelectual, mucho menos deberíamos aceptar el control transnacional privado sobre la investigación (sea cual sea). Ahora bien, uno puede querer o no querer cosas, pero es deber preguntarse primero, si lo que dicta la voluntad es posible de conseguir. A este respecto, ya Derrida había planteado la crisis:

Se plantea entonces una cuestión que no es sólo económica, jurídica, ética, política: ¿puede (y, si así es, ¿cómo?) la universidad afirmar una independencia incondicional, reivindicar una especie de soberanía, una especie muy original, una especie excepcional de soberanía, sin correr nunca el riesgo de lo peor, a saber, de tener debido a la abstracción imposible de esa soberana independencia- que rendirse y capitular sin condición, que permitir que se la tome o se la venda a cualquier precio? (Derrida, 1998, p. 5).

El Sistema Económico Latinoamericano (SELA) ha dejado en claro que ve a la Universidad como un lugar donde se han de resolver los problemas empresa dicta empresariales:

Como un proceso de educación continua, debería de iniciarse un esfuerzo dirigido a la actualización permanente tanto en profesores como empresarios, basados en estudios de casos reales. Esto permitiría no sólo el acercamiento entre ambos sectores, sino evaluar in situ las 
soluciones colectivas sugeridas, así como trasladar al aula, ejemplos concretos de desempeño y problemática empresarial (1997, p. 250).

Además, la lógica corporativa aspira imponer su perfil profesional (gerencial-empresarial) a las universidades, haciendo énfasis en las carreras 'productivas':

Énfasis fundamental para entender, administrar y valorizar la variable tecnológica a nivel de la empresa, a través de la formación en gestión tecnológica. Además, de ser incorporada como asignatura en todas las carreras de ingeniería, debería ser considerada a nivel de especialización y estudios de posgrado, de tal manera que podamos contar con un profesional a nivel gerencial que integre todos los conocimientos necesarios en la búsqueda de la competitividad empresarial (SELA, 1997, p. 250).

Como exponente de esta lógica, José Tellería sentencia que las críticas eventuales a las Universidades están en relación a los recursos que se asignan a los diversos sectores. Tellería implícitamente quiere dejar patente que hasta el más idiota comprende lo que supone la relación 'costo beneficio'. El costo de mantener áreas como humanidades, ¿está en relación a su beneficio?, ¿qué creen que responderían los empresarios y economistas neoliberales? 
Todos los miembros de la sociedad de un país han aprendido a evaluar, aunque sea por mera intuición, la relación costo / beneficio de recursos que se asignan a los diversos sectores. De ahí las críticas eventuales a las universidades (Tellería, 1997, p. 280).

Desde otro horizonte, más subterráneo y maquiavélico, se ha tenido claro también -como objetivo primordial- la capacitación urgente (adiestramiento de obediencia) de los sectores académicos, para que guarden confidencialidad y resguarden los resultados de la investigación, léase, 'derechos de propiedad intelectual' en manos de las nuevas 'corporaciones universitarias' o ‘universidades corporativas'. Así, en base a Correa (1992), el SELA enfatizó:

Tanto los sectores académicos como empresariales deberían prepararse con tiempo y adecuadamente para la profundización y la vinculación universidad-empresa, capacitándose en temas como formulación y gerencia de proyectos de investigación y desarrollo, negociación y redacción de contratos, regulación de la confidencialidad y protección de los resultados producto de la innovación (1997, p. 250).

A estas alturas, la línea divisoria entre el tipo de profesional que forma la universidad para la empresa y el tipo de docente que hay en su seno, se 
vuelve cada vez más imperceptible. Así, el docente e investigador universitario ha de ser, mediante petición expresa de la voluntad corporativa, un docente e investigador empresarial, que debe buscar financiamiento externo para justificar su utilidad en la nueva institución universitaria.

Los investigadores han debido salir a la búsqueda de financiamiento externo. La extensión se ha transformado, por una parte, con la preocupación por establecer actividades de difusión rentables y, por otra, ha surgido el área de prestación de servicios y producción de bienes educativos (asesorías, controles de laboratorios, actividades productivas) como actividades paralelas con más autonomía y fuertemente orientadas a la generación de nuevos ingresos (Ayarza, 1997, p. 341).

Tal parece que, si dicho 'síntoma' es una realidad vivida, es porque 'el futuro' de la Universidad tiene ya tiempo de estarse gestando, sin mayor resistencia por parte de la comunidad universitaria estatal. Responsables todos... cómplices todos. ¡Qué consuelo!

La figura de los profesores invitados, contemplada en muchas instituciones de enseñanza superior, es uno de los temas recurrentes en las discusiones académicas e institucionales al interior del manejo de la estructura

"Profesores invitados" sin grados universitaria. Si quizá en nuestro país tal discusión no se ha planteado ni seria ni urgentemente, en otros países de América Latina ya deja una estela árida de inconformidad. En el Perú -como paréntesis-, la discusión fue a la 
par de la denuncia sobre el nuevo sistema universitario que "tiene como objetivos primordiales la formación profesional vinculada al trabajo" (Zavala, 2003, p. 2) y no a la investigación.

El anteproyecto de la "Ley del Sistema de Educación Universitaria Nacional del Perú", dejaba un portillo abierto para que ingresaran a las aulas universitarias, una serie de charlatanes apadrinados por intereses privados, al describir que los profesores invitados tienen las características siguientes:

Aquellas personas naturales de reconocido prestigio nacional o internacional que POSEAN O NO GRADOS ACADÉMICOS O TÍTULOS PROFESIONALES, que cumplen tareas académicas o de investigación puntualmente señaladas en su contrato de invitación, y sujetas a plazo determinado; pueden ser renovados indefinidamente (Zavala, 2003, p. 6).

Respecto a este artículo, el manifiesto opositor a tales políticas universitarias advirtió:

Con ello se contratarán unos cuantos profesores graduados y el resto podrá ser un montón de charlatanes cuya calidad académica será evaluada justamente por esta Comisión Gobierno-Empresa Privada, movida por intereses opuestos a los de la universidad pública. De modo que los charlatanes promovidos por el sector privado, tendrán 
mayor puntaje académico que los graduados de las universidades. También servirá para una mayor manipulación política de los contratos de docencia (Zavala, 2003, p. 6).

Aunque las críticas anteriores se desprenden necesariamente del artículo en cuestión, es menester señalar que, si bien existe la mínima posibilidad de que entre los profesores invitados existan personas excepcionales que, a pesar de todo no posean grados académicos, lo más claro es que, a través de este artículo, se permitiría también la entrada de charlatanes a las aulas universitarias. Además, dicho artículo es una licencia que se arrojan las autoridades para que, en base a esta figura jurídica, puedan hacer entrar, mediante "argolla" y conveniencia privada, a las "estrellas supracadémicas", a un terreno cuyas reglas solo deben ser acatadas por la mayoría académica, y no por esa minoría que decide quiénes son esas "personas de reconocido prestigio nacional o internacional".

Si desde hace mucho tiempo las universidades públicas ya no deciden sobre tales tópicos, ¿quién entonces? La muchedumbre se cree educada porque repite lo que los medios de difusión les inculcan. Si los medios proclaman que Mentecato además de músico es el más grande intelectual del país... es porque es cierto. Son estos medios quienes se arrojan la potestad de establecer quiénes son los mejores entre los mejores, invisibilizando a unos y convirtiendo en "estrellas" a sus mismos presentadores de noticias y 
variedades. Y, si las autoridades de la educación justifican sus decisiones de elección (como profesores invitados) apoyados en la figura del "reconocido prestigio" que, a su vez, fue instaurado por dichos medios de difusión, es claro que, dentro de poco, la Universidad estará repleta de charlatanes sin título. En síntesis, por más genios que transiten por las calles sin títulos académicos; si no tienen títulos no deberían tener derecho a fungir como "profesores invitados". La grandeza de esos genios residiría también en estar fuera de la academia. Es cierto que hay que leerlos, estudiarlos y hasta idolatrarlos, pero no hay que matarlos convirtiéndolos en "profesores invitados", porque si se vive como docente, aunque se tengan diez postdoctorados, es porque en última instancia no se es la gran cosa.

Ningún genio podría soportar la estructura que impone el nuevo modelo de educación superior. Ningún genio caería tentado de metamorfosearse en el esclavo moderno que es el asalariado profesor universitario, carente cada vez más, de una actitud crítica y rebelde, pero sí, simpatizante de la obediencia servil, e inscrito en el nuevo orden de las políticas privadas de las ideologías transnacionales.

En el 2005, el Estado Español, con el fin de estandarizar los estudios universitarios con el resto de los países europeos, aprobó un Real Decreto que establece o abre el portillo para que el 50\% de los créditos de las asignaturas se complemente en actividades fuera de la Universidad, lo que

\section{Mano de obra estudiantil (gratis) para las empresas privadas}


podría convertirse en tiempo servido a Empresas Privadas; lo cual, descaradamente, significa que los estudiantes se ofrecerán como mano de obra gratis y cualificada para las empresas privadas.

Uno de los objetivos más visibles del Plan Bolonia (ya en Costa Rica), consiste en la formación de trabajadores cualificados que brindarán servicio gratuito a las empresas privadas, puesto que estas son quienes financian la educación por ellos recibidas.

$\mathrm{Si}$ antes, era visto con normalidad que el estudiante le retribuyera "gratuitamente" al Estado unas 300 horas o más de trabajo comunal universitario (TCU), puesto que este le financiaba su educación (de hecho me acuerdo, gratamente y con gratitud, de retribuir gratuitamente mis conocimientos impartiendo 'filosofía para niños') - hoy, la lógica de gratitud se reinvierte. Ya no se le agradecerá al Estado- Nación. A todos. A todos los ciudadanos integrantes de nuestra sociedad. No. Ahora se le agradecerá al Estado Empresarial. A unos pocos. A una minoría. Por lo que será lógico retribuir gratuitamente los conocimientos a la empresa privada, a esa minoría, a esa elite que nos "ayudó" con sus préstamos a concluir los estudios. 
La lógica de los defensores de la nueva voluntad universitaria-empresarial, es sostenida por personas con nombres y apellidos, que solo piensan en la rentabilidad, la productividad y la competencia; y en los intereses del mercado empresarial privado. Quizá, para intentar entender la lógica de estos defensores, haya que partir del postulado que asegura que, ninguno de ellos fue financiado - en sus estudios- por el Estado Benefactor. Habría que empezar creyendo que sus estudios fueron financiados por sus propias familias o en su defecto, por Bancos y Empresas Privadas. Solo, bajo este supuesto, podría ser posible entender la lógica de la élite que, exige que los demás pasen por ese purgatorio existencial, en donde los pobres simplemente deben resignarse a la imposibilidad de adquirir una educación universitaria: 'El que puede, puede, y el que no puede, debe servir al que puede'. Así reza la moral de los pudientes.

Si los académicos actuales estuviésemos inmersos en este mundo, en el que dan sus primeros pasos nuestros estudiantes ¿cuántos de nosotros podríamos haber completado los estudios universitarios? Nacidos en un Estado de Bienestar, que tose su agonía bajo las cenizas en las que se yergue el 'Estado Empresarial transnacional', y provenientes de familias pobres, no pudientes o no adineradas, primero tendríamos que haber pagado una educación secundaria privada, para poder concursar y optar por las becaspréstamos de los Bancos y empresas privadas. 
Segundo, si por cuestiones ajenas al deseo de estudiar, no hubiésemos podido terminar nuestros estudios ¿cómo pagaríamos la gran deuda?, ¿estaríamos esclavizados de por vida a pagar los intereses de nuestra deuda al Estado Empresarial, antítesis del caduco Estado Benefactor? Dirán que esas son las reglas de los nuevos tiempos.

Una vez aniquilada la gratuidad de la enseñanza superior, se sentará en su trono la educación para élites, como el monstruo que pisa fuerte.

Cuando se pertenece a la comunidad universitaria estatal, en un país que se hace llamar democrático, son poco perceptibles los cambios que se dan al interior de la institución, porque a pesar de que existen instancias como las "Asambleas Colegiadas Representativas", que en el papel se dice, "son las instancias superiores universitarias", hay otras instancias que, en la mayoría de las ocasiones, toman las decisiones más trascendentales y que determinan el devenir universitario, pienso aquí, en las decisiones de las rectorías y de los consejos universitarios. Se nos dirá que tales instancias se han elegido para que elijan por nosotros. He aquí el gran problema de la democracia representativa que se trae abajo la "democracia". Dicha "democracia representativa", no es más que una artimaña ideológica y legal para que una minoría minúscula elija por la mayoría. 
En el caso de las acciones institucionales, al interior de las universidades, funcionan de igual manera, por lo que, los cambios son perceptibles hasta que vemos que las transnacionales ingresan en semanas especiales (como las semanas universitarias) para vender u "ofrecer" sus servicios, sin que el resto de la comunidad universitaria haya participado en la elección de tales decisiones. Esto es solo un ejemplo, entre las muchas decisiones de las que no participamos, porque nos hemos asumido como una comunidad universitaria pasiva.

La visibilidad de los cambios universitarios, son poco visibles, porque trabajamos en ella, lo que no significa que no podamos verlos, pero para esto, es necesario tratar de ver la universidad un poco desde afuera, porque no vaya a ser que, sea visible solo cuando ya no sea posible no verla.

Por lo general, tenemos la sensación de que las cosas están cambiando, hasta que aparecen directrices que alteran nuestros hábitos: prohibiciones absolutas para fumar al aire libre (inexistencia de sitios -aunque marginados para fumadores); prohibiciones para que los jóvenes universitarios anden en patineta o jueguen a la bolita, pero por otro lado, se permiten perros de traba sueltos por la ciudad universitaria; conciertos que impiden impartir clases; sodas y restaurantes que llenan de olores las aulas; contratación de servicios privados en una institución estatal; apertura a intereses comerciales ajenos a la universidad. 
Así es, nos damos cuenta de que algo está pasando, solo cuando hay directrices que cambian nuestros hábitos, y, por lo general, atribuimos esos cambios a instancias generadas al interior de la institución; pero si ponemos más atención, de repente nos damos cuenta de que vienen de afuera, desde el gobierno, que altera y se inmiscuye en la autonomía universitaria mandando a veces a sus policías para que apaleen a estudiantes, profesores y administrativos.

La experiencia muestra, y ya varios autores lo de-muestran, que los cambios en las políticas educativas vienen impulsadas por las directrices gubernamentales, para que encajen en sus políticas de gobierno (no vamos a repetir que los políticos no son especialistas en educación, ni mucho menos).

Ahora bien, si resulta que somos más escépticos y curiosos, no necesitamos de mucho para percatarnos que aquellas directrices que creíamos caprichos de las autoridades universitarias, o incluso, que supimos venían implementadas por el gobierno, no deberíamos sorprendemos cuando nos percatemos que vienen desde arriba, nacidas de la voluntad global de poder de las grandes corporaciones, que buscan uniformarnos a todos mediante una educación estandarizada. 
Soldados de las corporaciones que controlan los gobiernos, son casi siempre los rectores y autoridades universitarias, pero también los docentes, estudiantes y administrativos que defienden las "políticas del progreso" (herencia de los ideales de la modernidad y de la ideología neoliberal) u optan por la indiferencia, como si fuera un escudo que los va proteger de lo que viene: mendigos del sistema (ex profesores, ex rectores y ex autoridades universitarias que podrán perder hasta la pensión) y esclavos del sistema: profesores y estudiantes activos que, para sobrevivir, han de convertirse en empresarios, que saldrán a la búsqueda de financiamiento para sus actividades, con el fin de justificar su permanencia y existencia en el nuevo Planeta S.A..

Estos soldados de la voluntad educativa global, son impulsadores de las políticas de evaluación y acreditación, las cuales toman cada vez más terreno, y que al final, terminarán por implantarse en todo el orbe. Lo que significa $; y$ hay que pronosticarlo!, que en un futuro muy cercano, será una fantasía imaginar una universidad no acreditada.

La universidades regionales han muerto -quizás nunca nacieron-; y las universidades nacionales tienen sus días contados, agonizan y morirán, al menos que... 
No me toca a mí plantear utopías, máxime de que no veo ningún terreno fértil para que sobrevivan. Sé que siempre hay optimistas de buen corazón y en especial, de buenas acciones, que se sacrifican por los demás, pero sus quehaceres son insignificantes en el nuevo imperio. Más bien, apenas entramos en la era de la Universidad Única que coincide con la era del egoísmo individual o de secta.

La nueva Universidad S.A., pone en peligro la supervivencia de las disciplinas humanistas (pertenecientes a las áreas de letras, artes y ciencias sociales) tal y como las entendemos hasta ahora. ¡Pero alertas!, que no nos sorprendan que las nuevas áreas que surjan en esta nueva estructura que se planta como "universitaria", exija que se le reconozca con el nombre de las anteriores; algo parecido a la práctica guerrera ancestral de los imperios, que construyen sus templos encima de los derrotados y que exigen a los súbditos su adoración, muchas veces aseverando que aunque es un nuevo dios sigue siendo el mismo. Lo que sí está por verse, y que no podemos ir más allá, es imaginar cuál será la visión de mundo que heredarán los educados por estas universidades acreditadas, que terminarán en el mismo canasto, para erigir finalmente la Universidad Única. Al parecer, va por buen camino El Absoluto. 
Que no sorprenda que las "reconocidas por las autoridades" como las mejores universidades del orbe sean las universidades privadas.

Acosta, Adrián. (2000). Estado, políticas y universidades en un periodo de transición. México: Fondo de Cultura Económica.

Ayarza, Hernán. (1997). Calidad, Evaluación Institucional y Acreditación. Caracas: CRESALC / UNESCO.

Boletín Oficial del Estado. (2005). Real Decreto. Ministerio de la Presidencia. Gobierno de España. Disponible en https://www.boe.es/buscar/doc.php?id=BOE-A-20051255

Derrida, Jacques. (1998). La universidad sin condición. Derrida en Castellano. Disponible en http://www.jacquesderrida.com.ar/textos/universidad-sincondicion.html

Hiller, Flora. (2003). Lo público, democrático y popular. Buenos Aires: Noveduc. 
Muela, Zapopan. (2005). La era del estado empresarial. Razón y Palabra, $\mathrm{n}^{\circ} 44$. Disponible en http://www.razonypalabra.org.mx/anteriores/n44/zmuela.html

Sistema Económico Latinoamericano. (Eds.). (1997). La Universidad como soporte fundamental del esfuerzo de competitividad empresarial de la región. Caracas: UNESCO / CRESALC.

Skilbeck, Malcolm. (2001). The University challenged: A review of international trends andissues with particular relevance to Ireland. Disponible en: $\mathrm{h}$ ttp://iua.webhost.heanet.ie/publications/documents/publications/2001/R eport_11.pdf

Tellería, José. (1997). Universidad - Gobierno- Empresa en América Latina y Bolivia. Caracas: UNESCO / CRESALC.

Trindade, Hélgio. (1997). Evaluación Institucional y Calidad Académica. Caracas: UNESCO / CRESALC

Wikipedia. Proceso de Bolonia (sf). Disponible en http://es.wikipedia.org/wiki/Proceso_de_Bolonia

Zavala, Carmen (2003) Privatización de universidades públicas. Lima. Disponible en: http://www.zavala.de/carmen/PrivatizacionUniversidadesPublicas.html 